\title{
Production of trans C18:1 and conjugated linoleic acid in continuous culture fermenters fed diets containing fish oil and sunflower oil with decreasing levels of forage
}

\author{
A. AbuGhazaleh ${ }^{\dagger}$ and B. N. Jacobson \\ Southern Illinois University Carbondale, IL 62901, USA
}

(Received 7 July 2006; Accepted 23 February 2007)

\begin{abstract}
Previously, feeding fish oil (FO) and sunflower seeds to dairy cows resulted in the greatest increases in the concentrations of vaccenic acid (VA, t11 C18:1) and conjugated linoleic acid (CLA) in milk fat. The objective of this study was to evaluate the effects of forage level in diets containing FO and sunflower oil (SFO) on the production of trans C18:1 and CLA by mixed ruminal microbes. A dual-flow continuous culture system consisting of three fermenters was used in a $3 \times 3$ Latin-square design. Treatments consisted of (1) 75:25 forage:concentrate (HF); (2) 50:50 forage:concentrate (MF); and (3) 25:75 forage:concentrate (LF). FO and SFO were added to each diet at 1 and $2 \mathrm{~g} / 100 \mathrm{~g}$ dry matter (DM), respectively. The forage source was alfalfa pellets. During 10-day incubations, fermenters were fed treatment diets three times daily (140 g/day, divided equally between three feedings) as TMR diet. Effluents from the last 3 days of incubation were collected and composited for analysis. The concentration of trans C18:1 (17.20, 26.60, and $36.08 \mathrm{mg} / \mathrm{g}$ DM overflow for HF, MF, and LF treatments, respectively) increased while CLA (2.53, 2.35 , and $0.81 \mathrm{mg} / \mathrm{g} D M$ overflow) decreased in a linear manner $(\mathrm{P}<0.05)$ as dietary forage level decreased. As dietary forage levels decreased, the concentrations of $\mathrm{t} 10 \mathrm{C18:1}(0.0,10.5,33.5 \mathrm{mg} / \mathrm{g} \mathrm{DM})$ in effluent increased $(\mathrm{P}<0.05)$ and t10c12 CLA $(0.08,0.12,0.35 \mathrm{mg} / \mathrm{g} D M)$ tended to increases $(\mathrm{P}<0.09)$ linearly. The concentrations of VA $(14.7,13.9,0.0 \mathrm{mg} / \mathrm{g} \mathrm{DM})$ and c9t11 CLA $(1.78,1.52,0.03 \mathrm{mg} / \mathrm{g} D \mathrm{M})$ in effluent decreased in a linear manner $(\mathrm{P}<0.05)$ as dietary forage levels decreased.

Decreasing dietary forage levels resulted in 110 C18:1 and t10c12 CLA replacing VA and c9t11 CLA, respectively, in fermenters fed FO and SFO.
\end{abstract}

Keywords: conjugated linoleic acid, fish oil, forage level, sunflower oil, trans C18:1

\section{Introduction}

The different positional and geometric isomers of conjugated linoleic acid (CLA) confer different health effects on mammals (Belury, 2002). The c9t11 CLA isomer has been shown to be anti-carcinogenic (Ip et al., 1999), while the t10c12 CLA isomer has been shown capable of decreasing body fat and increasing lean body mass (Park et al., 1999). The t10c12 CLA isomer also decreases fat concentration in dairy cows' milk in a dose-dependent fashion (Peterson et al., 2002). These effects on mammals have encouraged research efforts to identify methods of increasing the c9t11 CLA isomer and to understand the mechanisms of $t 10 \mathrm{c} 12 \mathrm{CLA}$ production so that its synthesis would occur only when desired.

Conjugated linoleic acid and trans C18:1 fatty acids (FA) are produced during biohydrogenation of unsaturated FA in the rumen (AbuGhazaleh et al., 2005; Harfoot \&

\footnotetext{
${ }^{\dagger}$ E-mail: aabugha@siu.edu
}

Hazlewood, 1988) and are subsequently incorporated into milk and meat of ruminant animals. Formation of trans C18:1 and CLA in the rumen are influenced by dietary supplementation with unsaturated vegetable oils (AbuGhazaleh et al., 2003; Loor et al., 2004a and b) or changes in rumen $\mathrm{pH}$ as a result of alterations in dietary forage to concentrate ratios (F:C) (Piperova et al., 2002; Loor et al., 2003; Sackmann et al., 2003).

Previous studies have demonstrated an increase in the vaccenic acid (VA) and c9t11 CLA content of bovine milk fat when fish oil (FO) and linoleic acid oil sources were added to dairy cattle rations containing $50 \%$ forage (AbuGhazaleh et al., 2000; Whitlock et al., 2002). Studies examining the effect of forage or concentrate feeding on the distribution of trans C18:1 and CLA isomers in the rumen (Loor et al., 2004a) or ruminant fat (Sackmann et al., 2003; Aharoni et al., 2004; Loor et al., 2005) have used only vegetable oils or FO. Feeding high concentrate diets (Piperova et al., 2002) or low 
forage diets supplemented with vegetable oils rich in linoleic acid or FO (Loor et al., 2004a) altered ruminal biohydrogenation resulting in $t 10$ rather than VA being the predominant trans C18:1 intermediate. Alterations in the profile of trans C18:1 intermediates formed in the rumen have direct consequences on the supply of VA available for endogenous conversion in the mammary gland into c9t11 CLA (Bauman et al., 1999). Previously, AbuGhazaleh et al. (2000, 2003) and Whitlock et al. (2002) demonstrated that the greatest concentrations of VA and c9t11 CLA in milk fat and rumen contents can be obtained by adding FO along with linoleic acid fat source to ruminant animals' diet. The aim of this study was to investigate how changing dietary forage levels in diets containing FO and sunflower oil (SFO) affect trans C18:1 and CLA isomers distribution in the rumen.

\section{Material and methods}

\section{Experiment protocol}

Three $1700 \pm 12 \mathrm{ml}$ dual-flow continuous culture fermenters (Stern \& Hoover, 1990) were used in a $3 \times 3$ Latin square over three periods of 10 days each. Each experimental period consisted of 7 days for adaptation and followed by 3 days for sample collection. Treatments used in this study were as follows: (1) 75:25 F:C (HF); (2) 50:50 $\mathrm{F}: \mathrm{C}$ (MF); and (3) 25:75 F:C (LF). Menhaden FO (Omega Protein Inc., Hammond, LA) and SFO (purchased from a local store) were added to each diet at 1 and $2 \mathrm{~g} / 100 \mathrm{~g}$ dry matter (DM) basis, respectively. Maize, soya-bean meal, limestone, vitamins and minerals made up the concentrate mix (Table 1). The forage source was alfalfa pellets. A total of $140 \mathrm{~g}$ of feed (DM basis) was placed in each fermenter daily in three equal portions at 0800,1500 , and $2100 \mathrm{~h}$.

\section{Continuous culture}

Whole ruminal contents were taken from two ruminally fisulated Holstein cows fed a 50:50 F:C diet. At each

Table 1 Ingredient and chemical composition of treatment diets

\begin{tabular}{lrrrr}
\hline \hline & \multicolumn{3}{c}{ Treatments $^{\dagger}$} & \\
\cline { 2 - 3 } & HF & MF & LF & s.d. \\
\hline Ingredients (g/100 g DM) & & & & \\
$\quad$ Alfalfa & 75.00 & 50.00 & 25.00 & \\
Maize & 19.70 & 38.70 & 57.70 & \\
Soya-bean meal, 48\% & 2.00 & 8.00 & 14.00 & \\
Sunflower oil & 2.00 & 2.00 & 2.00 & \\
Fish oil & 1.00 & 1.00 & 1.00 & \\
Vitamin and mineral mix & 0.30 & 0.30 & 0.30 & \\
Chemical composition (g/100 g DM) & & & \\
Crude protein & 17.82 & 17.74 & 17.63 & 0.13 \\
Neutral-detergent fibre & 34.78 & 26.05 & 17.38 & 0.32 \\
Acid-detergent fibre & 22.77 & 16.33 & 9.88 & 0.29 \\
Ether extract & 6.04 & 6.43 & 6.82 & 0.16 \\
Ash & 6.29 & 5.40 & 4.70 & 0.14 \\
Total fatty acids & 3.77 & 3.93 & 4.25 & 0.10 \\
\hline \hline
\end{tabular}

${ }^{\dagger} \mathrm{HF}=75: 25 \mathrm{~F}: \mathrm{C}, \mathrm{MF}=50: 50 \mathrm{~F}: \mathrm{C}$, and $\mathrm{LF}=25: 75 \mathrm{~F}: \mathrm{C}$. collection time, approximately $4.5 \mathrm{~kg}$ of ruminal content were taken from the cow $4 \mathrm{~h}$ after feeding, strained through two layers of cheesecloth and transported to the laboratory in a sealed container and used within $20 \mathrm{~min}$. Fermenter canisters ( $15 \mathrm{~cm}$ long and $12.5 \mathrm{~cm}$ wide) were filled with approximately $1300 \mathrm{ml}$ of rumen fluid and $400 \mathrm{ml}$ of prewarmed buffer with urea added (Weller \& Pilgrim, 1974). Solids and liquid dilution rates were adjusted, twice daily, to values of 3 and $10 \%$ per $h$, respectively, by regulation of buffer input and filtrate removal rates. Fermenters were constantly mixed at 120 r.p.m. via a magnetic impeller stirrer unit, purged with $\mathrm{N}^{2}$ gas $(80 \mathrm{ml} / \mathrm{min})$ and temperature was maintained at $39^{\circ} \mathrm{C}$. The $\mathrm{pH}$ was measured daily at 0800 , 1500 , and $2100 \mathrm{~h}$ using a portable pH meter (Accumet* AP85 Portable, Fisher Scientific, Pittsburgh. PA).

\section{Sample collection and analysis}

Effluent from each fermenter was collected into 5-I plastic jugs submerged approximately three-quarters into a $4^{\circ} \mathrm{C}$ water bath. The solid and liquid effluent volumes were cataloged daily before the morning feeding and discarded until the final 3 days of each period. On the last 3 days, the solid and liquid portions were combined, homogenised on a stir plate and a $10 \%$ volume subsample was collected and stored at $-5^{\circ} \mathrm{C}$. Subsamples from each fermenter were composited for days 8,9 and 10 resulting in one sample per fermenter per period. Samples were thawed in a $50^{\circ} \mathrm{C}$ waterbath, transferred into $250 \mathrm{ml}$ plastic bottles (10 cm long and $5 \mathrm{~cm}$ wide) and centrifuged (Beckman J221) at 15000 r.p.m. for $15 \mathrm{~min}$, after which the supernatant was removed. This process was repeated until all liquid in the thawed sample was removed. The bottle and fiber pellet was stored at $-80^{\circ} \mathrm{C}$ for $48 \mathrm{~h}$, freeze dried and then ground to $1 \mathrm{~mm}$ using a Willey mill (Arthur Thomas Company, Philadelphia, PA).

Samples of alfalfa pellets and concentrate mixes were collected twice each period (days 5 and 10) and stored at $-20^{\circ} \mathrm{C}$ until analysis. Samples were freeze dried for at least $48 \mathrm{~h}$, then ground through a 2-mm screen of a standard Wiley mill (model 3; Arthur H. Thomas Co., Philadelphia, PA) and composited by period. Composites were analysed for crude protein (CP), ether extract, and ash according to Association of Official Analytical Chemists methods (1997). Samples were reground (Brinkman ultracentrifuge mill) through a 1-mm screen and analysed for neutral-detergent fibre (NDF, procedure $B$ of Van Soest et al. (1991)) and acid detergent fibre (ADF, Robertson and Van Soest, 1981) using an ANKOM fiber analyser and filter bag technique (ANKOM Technology Corp., Fairport, NY).

Feed and effluent samples were methylated using $\mathrm{NaOCH}_{3}$ and $\mathrm{HCl}$ two steps procedure as outlined by Kramer et al. (1997) and analysed in triplicate for FA on a Shimadzu GC-2010 gas chromatograph (Shimadzu Scientific Instruments, Inc., Columbia, Maryland, USA) equipped with a flame ionisation detector and a Supelco 100-m SP-2560 fused silica capillary column $(0.25 \mathrm{~mm}$ i.d. $\times 0.2 \mu \mathrm{m}$ film thickness; Supelco Inc., Bellefonte, PA). The helium carrier 
gas was maintained at a linear velocity of $23 \mathrm{~cm} / \mathrm{s}$. The oven temperature was programmed at $170^{\circ} \mathrm{C}$ for $50 \mathrm{~min}$, then increased at $5^{\circ} \mathrm{C} / \mathrm{min}$ to $249^{\circ} \mathrm{C}$ and held for $10 \mathrm{~min}$. The injector and detector temperatures were set at $255^{\circ} \mathrm{C}$. One milligram of nonadecanoic acid (C19:0; $1 \mathrm{mg} / \mathrm{ml}$ benzene) was added to all samples before methylation as an internal standard. Peaks were identified by comparing the retention times with those of corresponding standards (Nu-Chek-Prep., Elysian, MN; Supelco, Bellefonte, PA; and Larodan Fine Chemicals, Malmo, Sweden). The trans C18:1 isomers that were not available commercially (trans-6/8, trans-10, trans-12, trans-13/14) were identified according to the elution sequence reported by Loor et al. (2004b). Conjugated linoleic acid isomers were identified according to the elution sequence reported by Roach et al. (2002) using Nu-Check-Prep \#UC59mx (Elysian, MN; Supelco). Retention times for $c 9 t 11, t 10 c 12$, and $t 9 t 11$ were confirmed with pure standards (Matreya LLC, Pleasant Gap, PA).

A summary of dietary ingredients and chemical composition of the experimental diets is shown in Table 1. Dietary $\mathrm{CP}$ was similar across diets averaging $17.7 \mathrm{~g} / 100 \mathrm{~g}$ DM. Dietary ADF and NDF decreased as dietary forage level decreased (Table 1). Daily input of total FA (g/day) was also affected by dietary treatments, increasing as dietary forage decreased. Supplies of oleic and linoleic acids increased while linolenic acid decreased as dietary forage level decreased (Table 2). All treatments had an equal supply of C18:0, C20:5, and C22:6.

\section{Statistical analysis}

Data were analysed using the general linear model procedure of (Statistical Analysis Systems Institue, Inc., Cary, NC) According to the following statistical model:

$$
Y_{i j k}=\mu+F_{i}+D_{j}+P_{k}+e_{i j k}
$$

where $Y_{i j k}=$ the observation; $\mu=$ overall mean; $F_{i}=$ fermenter effect; $D_{j}=$ diet effect; $P_{k}=$ period effect and $e_{i j}=$ residual error associated with $Y_{i j k}$.

Table 2 Fatty acids intake (g/day)

\begin{tabular}{lccc}
\hline & \multicolumn{3}{c}{ Treatments $^{\dagger}$} \\
\cline { 2 - 4 } & HF & MF & LF \\
\hline Fatty acid & & \\
C14:0 & $0.11 \pm 0.01$ & $0.11 \pm 0.01$ & $0.10 \pm 0.01$ \\
C16:0 & $0.63 \pm 0.01$ & $0.64 \pm 0.02$ & $0.66 \pm 0.01$ \\
C18:0 & $0.18 \pm 0.01$ & $0.18 \pm 0.01$ & $0.19 \pm 0.01$ \\
C18:1 c9 & $0.76 \pm 0.03$ & $0.90 \pm 0.04$ & $1.14 \pm 0.07$ \\
C18:2 n6 & $1.99 \pm 0.05$ & $2.26 \pm 0.09$ & $2.70 \pm 0.13$ \\
C18:3 n3 & $0.48 \pm 0.02$ & $0.34 \pm 0.02$ & $0.21 \pm 0.01$ \\
C20:5 n3 & $0.13 \pm 0.01$ & $0.13 \pm 0.01$ & $0.12 \pm 0.01$ \\
C22:5 n3 & $0.04 \pm 0.01$ & $0.03 \pm 0.01$ & $0.03 \pm 0.01$ \\
C22:6 n3 & $0.13 \pm 0.01$ & $0.13 \pm 0.01$ & $0.12 \pm 0.01$ \\
Total & $5.29 \pm 0.12$ & $5.50 \pm .14$ & $5.95 \pm 0.12$ \\
\hline
\end{tabular}

${ }^{\dagger} \mathrm{HF}=75: 25 \mathrm{~F}: \mathrm{C}, \mathrm{MF}=50: 50 \mathrm{~F}: \mathrm{C}$, and $\mathrm{LF}=25: 75 \mathrm{~F}: \mathrm{C}$.
The linear and quadratic effects of treatments were analysed by orthogonal contrasts. Least-square means are reported throughout and significance threshold was set at $P \leq 0.05$ and the trend at $P \leq 0.10$.

\section{Results}

As expected, fermenter $\mathrm{pH}$ was affected by dietary forage level (Figure 1), averaging 6.55, 6.15, and 5.65 for diet $\mathrm{HF}$, MF and LF, respectively.

Effect of diet on effluent FA concentrations ( $\mathrm{mg} / \mathrm{g}$ of DM) is presented in Table 3. The concentration of trans C18:1 increased $(P<0.03)$ in a linear manner as dietary forage level decreased. Compared with $\mathrm{HF}_{\text {, }}$ the concentration of trans C18:1 increased by 55 and $110 \%$ as dietary forage level decreased to 50 and $25 \%$, respectively. Dietary treatments also affected the distributions of trans C18:1 isomers (Table 3). The concentration of VA decreased whereas the concentration of $t 10$ C18:1 increased $(P<0.01)$ in a linear manner as dietary forage level decreased. Vaccenic acid and t10 C18:1 were the predominant trans C18:1 isomers in the HF and LF diets, respectively, accounting for 85 and $93 \%$ of total trans C18:1 isomers, respectively. The concentrations of trans-6/8, trans-9, and trans-12 was not affected $(P>0.15)$ by treatment diets (Table 3$)$. Trans-13/14 was detected only in the LF fermenter and was the second major trans C18:1 isomer.

Dietary treatments also affected effluent CLA concentrations and isomers distribution (Table 3 ). The concentration of CLA decreased linearly $(P=0.03)$ as dietary forage level decreased. The concentrations of c9t11 CLA decreased $(P<0.02)$, whereas the concentration of t10c12 CLA tended to increase $(P<0.09)$ in a linear manner as dietary forage decreased. Cis 9 t11 and $t t$ CLA were the major isomers in the HF diet accounting for 70 and $20 \%$ of total CLA, respectively, whereas t10c12 and $t 11 t 13$ CLA were the predominate isomers in the LF diet accounting for 43 and $30 \%$ of total CLA (Table 3).

The effect of diet on C18 unsaturated FA biohydrogenation is presented in Table 4. As dietary forage decreased, biohydrogenation of linoleic and linolenic acids decreased

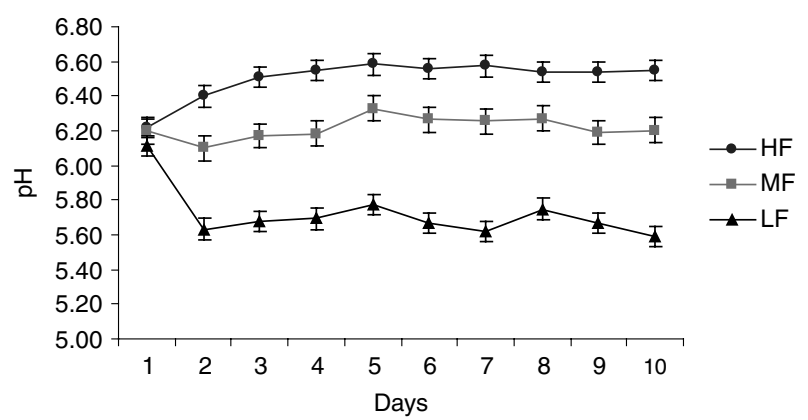

Figure $1 \mathrm{pH}$ in continuous culture fermenters for $\mathrm{HF}=75: 25 \mathrm{~F}: \mathrm{C}$; MF $=50: 50 \mathrm{~F}: \mathrm{C}$; and 25:75 F:C. Standard errors of the means were 0.06 , 0.07 , and 0.06 , respectively. 
Table 3 Effect of treatment diets on the outflow fatty acids $(\mathrm{mg} / \mathrm{g}$ of dry matter)

\begin{tabular}{|c|c|c|c|c|c|c|}
\hline & \multicolumn{3}{|c|}{ Treatments $^{\dagger}$} & \multirow[b]{2}{*}{ s.e. } & \multicolumn{2}{|c|}{ Contrast $^{\ddagger}$} \\
\hline & $\mathrm{HF}$ & MF & LF & & Lin & Quad \\
\hline \multicolumn{7}{|l|}{ Fatty acid } \\
\hline C14:0 & 1.27 & 1.39 & 1.31 & 0.12 & 0.80 & 0.53 \\
\hline C16:0 & 11.06 & 11.72 & 10.92 & 0.36 & 0.81 & 0.25 \\
\hline C18:0 & 12.53 & 6.98 & 4.95 & 0.57 & 0.05 & 0.14 \\
\hline C18:1 trans & 17.20 & 26.60 & 36.08 & 2.47 & 0.03 & 0.90 \\
\hline$t 6 / 8$ & 0.91 & 0.86 & 0.50 & 0.09 & 0.12 & 0.54 \\
\hline$t 9$ & 0.66 & 0.37 & 0.00 & 0.16 & 0.11 & 0.90 \\
\hline$t 10$ & 0.00 & 10.54 & 33.54 & 0.97 & 0.01 & 0.23 \\
\hline$t 11$ & 14.65 & 13.89 & 0.00 & 0.84 & 0.01 & 0.17 \\
\hline$t 12$ & 0.98 & 0.94 & 0.60 & 0.18 & 0.26 & 0.56 \\
\hline$t 13 / 14$ & 0.00 & 0.00 & 1.44 & 0.06 & 0.01 & 0.01 \\
\hline C18:1 c9 & 8.08 & 8.99 & 13.30 & 0.53 & 0.02 & 0.12 \\
\hline C18:1 c11 & 0.89 & 1.24 & 1.43 & 0.13 & 0.10 & 0.69 \\
\hline C18:2 n6 & 7.14 & 9.48 & 18.81 & 1.05 & 0.02 & 0.15 \\
\hline C18:3 n3 & 1.77 & 1.21 & 1.64 & 0.13 & 0.62 & 0.14 \\
\hline $\mathrm{CLA}^{\S}$ & 2.53 & 2.35 & 0.81 & 0.21 & 0.03 & 0.12 \\
\hline$c 9+11$ & 1.78 & 1.52 & 0.03 & 0.19 & 0.02 & 0.12 \\
\hline$t 10 c 12$ & 0.08 & 0.12 & 0.35 & 0.03 & 0.09 & 0.48 \\
\hline$c 9 c 11$ & 0.03 & 0.07 & 0.00 & 0.02 & 0.34 & 0.09 \\
\hline$t 11 t 13$ & 0.13 & 0.14 & 0.24 & 0.01 & 0.02 & 0.09 \\
\hline$t t$ & 0.51 & 0.50 & 0.20 & 0.06 & 0.06 & 0.19 \\
\hline C20:3 n3 & 0.07 & 0.09 & 0.19 & 0.19 & 0.26 & 0.61 \\
\hline C20:5 n3 & 0.73 & 0.87 & 1.01 & 0.10 & 0.21 & 0.98 \\
\hline $\mathrm{C} 22: 5 \mathrm{n} 3$ & 0.43 & 0.54 & 0.59 & 0.01 & 0.01 & 0.19 \\
\hline $\mathrm{C} 22: 6 \mathrm{n} 3$ & 0.85 & 1.10 & 1.28 & 0.14 & 0.18 & 0.85 \\
\hline Total fatty acids & 81.05 & 89.69 & 110.58 & 2.13 & 0.01 & 0.14 \\
\hline
\end{tabular}

${ }^{\dagger} \mathrm{HF}=75: 25 \mathrm{~F}: \mathrm{C}, \mathrm{MF}=50: 50 \mathrm{~F}: \mathrm{C}$, and $\mathrm{LF}=25: 75 \mathrm{~F}: \mathrm{C}$.

${ }^{\ddagger}$ Linear and quadratic effects.

${ }^{\S} \mathrm{CLA}=$ conjugated linoleic acid.

linearly $(P<0.03)$. Biohydrogenation of oleic acid also tended to decrease linearly $(P=0.06)$ with decreasing forage proportion in the diet.

\section{Discussion}

Trans C18:1 in effluents accounted for 21, 30, and 33\% of total FA for diet HF, MF, and LF, respectively (Table 3). The increase in concentration of trans C18:1 in LF $(36.1 \mathrm{mg} / \mathrm{g}$ of effluent) compared with HF $(17.20 \mathrm{mg} / \mathrm{g})$ indicated that

Table 4 Effect of treatment diets on the biohydrogenation (\%) of unsaturated fatty acid

\begin{tabular}{cccccccc}
\hline \hline & \multicolumn{3}{c}{ Treatments $^{\dagger}$} & & \multicolumn{2}{c}{ Contrast $^{\ddagger}$} \\
\cline { 2 - 4 } \cline { 7 - 8 } & HF & MF & LF & s.e. & Lin & Quad \\
\hline Fatty acid & & & & & & \\
C18:1 c9 & 55.6 & 45.7 & 44.4 & 4.22 & 0.06 & 0.19 \\
C18:2 n6 & 88.6 & 87.5 & 71.3 & 3.15 & 0.02 & 0.12 \\
C18:3 n3 & 87.4 & 83.5 & 66.1 & 4.21 & 0.02 & 0.15 \\
\hline \hline
\end{tabular}

${ }^{\dagger} \mathrm{HF}=75: 25 \mathrm{~F}: \mathrm{C}, \mathrm{MF}=50: 50 \mathrm{~F}: \mathrm{C}$, and $\mathrm{LF}=25: 75 \mathrm{~F}: \mathrm{C}$.

${ }^{\ddagger}$ Linear and quadratic effects. low forage diets promote trans C18:1 accumulation. The linear increase in trans C18:1 concentration as dietary forage level decreased may have resulted, in part from the higher unsaturated C18 FA input for MF and LF diets compared with HF diet (Table 2). Daily input for unsaturated C18 FA was higher by 8 and 25\% for MF and LF diets compared with HF diet. Incomplete biohydrogenation of unsaturated C18 FA in the rumen results in trans C18:1 accumulation (Harfoot \& Hazlewood, 1988). Additionally, high trans C18:1 accumulation observed in the LF diet may have resulted from inhibiting the reductase enzyme in ruminal micro-organisms responsible for the terminal hydrogenation of trans C18:1 to C18:0. The low concentration of C18:0 observed in LF effluent supports the suggestion that inhibition occurred at the final reductase step. The linear increase in trans C18:1 concentration indicates that low ruminal $\mathrm{pH}$ favours trans $\mathrm{C18:1}$ accumulation. Low ruminal $\mathrm{pH}$, caused by a high-concentrate diet, increased the accumulation of trans C18:1 in other studies (Karlscheur et al., 1997; Piperova et al., 2002; Loor et al., 2004b). Although this study and others (Karlscheur et al., 1997; Piperova et al., 2002; Loor et al., 2004b) clearly show that low rumen $\mathrm{pH}$ promotes trans $\mathrm{C} 18: 1$ accumulation, the mechanism is still unknown. The accumulation of trans C18:1 under low rumen $\mathrm{pH}$ conditions may be caused by altering the rumen ecosystem and/or inhibiting the reductase activity of ruminal microorganisms, causing the accumulation of trans C18:1. Low rumen $\mathrm{pH}$ has been shown to have a negative effect on microbial growth (Russell \& Dombrowski, 1980; Martin et al., 2002), particularly on the growth of cellulolytic bacteria, the main rumen biohydrogenating bacteria, (Harfoot \& Hazlewood, 1988).

Six trans C18:1 isomers were identified in effluents (Table 3). As dietary forage level decreased, VA concentration decreased, but t10 C18:1 concentration increased linearly. This shift indicates that incremental increases in concentrate level have the potential to enhance ruminal production of $t 10 \mathrm{C} 18: 1$. To our knowledge, no in vivo or in vitro experiment has evaluated the ruminal distribution of trans C18:1 isomers, primarily VA and t10 C18:1, in response to a graded decrease of dietary forage level at a constant level of supplemental FO and SFO. When cows were switched from a control diet $(60: 40 \mathrm{~F}: \mathrm{C})$ to a highconcentrate diet $(25: 75 \mathrm{~F}: \mathrm{C})$, the proportion of $t 10 \mathrm{C} 18: 1$ increased, concomitant with decreases in VA (Piperova et al., 2002). Additionally, t10 C18:1 replaced VA as the predominant trans C18:1 isomer in the rumen when high concentrate-low fibre diets were fed to cows (Griinari et al., 1998) and steers (Sackmann et al., 2003). Under such conditions, Bauman et al. (1999) proposed a putative pathway for the production of $t 10 \mathrm{C} 18: 1$ where the $t 10 \mathrm{c} 12$ CLA-producing bacteria become predominant in the rumen resulting in formation of $110 \mathrm{C} 12 \mathrm{CLA}$ as the first intermediate during linoleic acid biohydrogenation. Hydrogenation of the c12 bond would then result in formation of $t 10$, analogous to the production of VA from c9t11 CLA. High concentrate diets have been shown to promote the growth 
of Megasphera elsdenii YJ-4 which can convert linoleic acid to $t 10 c 12$ CLA (Kim et al., 2002). Furthermore, feeding high grain diets to steers has been shown to stimulate the growth of the YE34 strain of Megasphera elsdenii and cause a rapid decline in Butyrivibrio fibrisolvens YE44 (Klieve et al., 2003) and its is well established that VA is an intermediate of linoleic acid metabolism by isolates of Butyrivibrio fibrisolvens (Harfoot \& Hazlewood, 1988).

The t10 C18:1 could also arise via the isomerisation of oleic acid (AbuGhazaleh et al., 2005). The fact that $t 10$ accounted for $93 \%$ of total trans C18:1 isomers with the LF diet compared with the $37 \%$ and $60 \%$ reported by Griinari et al. (1998) and Sackmann et al. (2003), when high-concentrate diets supplemented with linoleic acid oil source were fed, supports our previous finding that docosahexaenoic acid (C22:6; DHA) in F0 blocks the final step in the biohydrogenation of unsaturated C18 FA causing trans C18:1 accumulation (AbuGhazaleh and Jenkins, 2004). What seems evident from this experiment and others (Griinari et al., 1998; Sackmann et al., 2003) is that a supply of high linoleic acid oil along with FO under low $\mathrm{pH}$ condition has the greatest potential to enhance $t 10$ C18:1 production in the rumen. These conditions simultaneously eliminated or reduced concentration of $t 6 / 8, t 9$, and $t 12$ C18:1 in effluent, but increased concentration of t13/14 C18:1. Such changes in effluent trans C18:1 isomers profile may suggest a possible alteration in the microbial ecosystem and/or enzyme activities as a result of altering the proportion of forage in the diet. The total absence of t10 and VA in effluents of HF and LF, respectively, should be taken with precaution since the separation of these two isomers can be difficult when their concentrations are very different. Indeed, a small VA shoulder peak was observed in some LF t10 peaks, however, the ratio of VA to t10 was consistently less than 1:30.

The effect of dietary treatments on CLA is presented in Table 3. Total concentrations of CLA were highest in the $\mathrm{HF}$, intermediate in MF, and least in LF indicating that CLA formation is favoured by high ruminal $\mathrm{pH}$. Troegeler-Meynadier et al. (2003) also reported more CLA accumulation in rumen cultures incubated at high than low $\mathrm{pH}$. The predominate CLA isomer detected in the $\mathrm{HF}$ and LF were $c 9 t 11 \mathrm{CLA}$ and $t 10 \mathrm{C} 12 \mathrm{CLA}$, respectively. In ewes, duodenal flow of $t 10 c 12$ CLA increased and $c 9 t 11$ CLA decreased in response to graded increments of dietary concentrate with a constant level $(7.4 \mathrm{~g} / 100 \mathrm{~g}$ diet DM) of supplemental FA from soya-bean oil (Kucuk and Hess, 2004). Our results support the findings of others (Beaulieu et al., 2002; Duckett et al., 2002; Shingfield et al., 2005) that high concentrate diets support t10c12 CLA formation in the rumen. Replacing incremental portions of red clover with maize grain in dual-flow continuous cultures resulted in a linear increase in the output of t10c12 CLA into effluent (Latham et al., 1972). Shingfield et al., (2005) reported higher c9t11 CLA concentration in milk when cows were fed a high forage diet $(65: 35)$ than low forage diet (35:65) with FO and
SFO as lipid supplements. These results indicates that incremental grain or concentrate have the potential to enhance ruminal production of $t 10 c 12$ CLA. Trans $10 c 12$ CLA is a potent inhibitor of fat synthesis (Baumgard et al., 2002). What seems evident from this study and others (Beaulieu et al., 2002; Duckett et al., 2002; Kucuk and Hess, 2004) is that a high linoleic acid oil source along with low dietary $\mathrm{F}: \mathrm{C}$ ratio has the greatest potential to increase $t 10 \mathrm{c} 12 \mathrm{CLA}$. The $111+13 \mathrm{CLA}$ was the second predominant isomer in the LF. A similar increase in $t 11 t 13$ CLA concentration was also reported by Loor et al., (2004b) when linseed oil was added to a highconcentrate diet. The formation of these different CLA isomers in ruminal cultures provides comparative evidence for the existence of alternative pathways for the biohydrogenation of C18 polyunsaturated FA other than those established by Harfoot \& Hazlewood (1988).

The biohydrogenation C18 unsaturated FA were affected by treatment diets (Table 4). The biohydrogenation of oleic, linoleic and linolenic acids was greater in $\mathrm{HF}$ and MF than LF diet. Wang et al. (2002) and Troegeler-Meynadier et al. (2003) also reported decreased biohydrogenation of linoleic and linolenic acids at low pH in vitro. Under in vivo conditions, Sackmann et al. (2003) and Kucuk and Hess (2004) have shown that higher dietary forage levels increase biohydrogenation of dietary C18 unsaturated FA. The decreased biohydrogenation of linoleic and linolenic acids with the LF diet suggested a lower biohydrogenation activity by cultures microbes. The low biohydrogenation values for oleic acid in this study compared with others (Duckett et al., 2002; Sackmann et al., 2003Kucuk and Hess, 2004) may have resulted from the DHA effect on the reduction step in the biohydrogenation (AbuGhazaleh and Jenkins, 2004).

\section{Conclusion}

Dietary forage level affected trans C18:1 and CLA concentrations in effluent with more trans C18:1 and less CLA accumulation seen in LF diet. Decreasing dietary forage levels resulted in $t 10 \mathrm{C} 18: 1$ and $t 10 \mathrm{c} 12 \mathrm{CLA}$ replacing VA

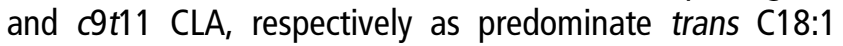
and CLA isomers in the rumen. Our results showed that a supply of high linoleic acid oil along with FO under low pH condition has the greatest potential to enhance t10 C18:1 and $110 \mathrm{c} 12 \mathrm{CLA}$ production in the rumen.

\section{References}

AbuGhazaleh AA and Jenkins TC 2004. Short communication: docosahexaenoic acid promotes vaccenic acid accumulation in mixed ruminal cultures when incubated with linoleic acid. Journal of Dairy Science 87, 1047-1050.

AbuGhazaleh AA, Riley MB, Thies EE and Jenkins TC 2005. Dilution rate and $\mathrm{pH}$ effects on the conversion of oleic acid to trans C18:1 positional isomers in continuous cultures. Journal of Dairy Science 88, 4334-4341.

AbuGhazaleh AA, Schingoethe DJ, Hippen AR and Kalscheur KF 2003. Milk conjugated linoleic acid response to fish oil supplementation of diets differing in fatty acid profiles. Journal of Dairy Science 86, 944-953.

AbuGhazaleh AA, Schingoethe DJ, Hippen AR and Kalscheur KF 2004. Milk conjugated linoleic acid response from cows fed fish meal and extruded 
soybeans for an extended period of time. Journal of Dairy Science 87, 1758-1765.

AbuGhazaleh AA, Schingoethe DJ, Hippen AR and Whitlock LA 2000. Feeding fish meal and extruded soybeans enhances the conjugated linoleic acid (CLA) content of milk. Journal of Dairy Science 85, 624-631.

Aharoni Y, Orlov A and Brosh A 2004. Effects of high-forage content and oilseed supplementation of fattening diets on conjugated linoleic acid (CLA) and trans fatty acids profiles of beef lipid fractions. Animal Feed Science and Technology 117, 43-60.

Association of Official Analytical Chemists 1997. Official methods of analysis, 16th edition. AOAC, Gaithersburg, MD, USA.

Bauman DE, Baumgard LH, Corl BA and Griinari JM 1999. Biosynthesis of conjugated linoleic acid in ruminants. Proceedings of the American Society of Animal Science, 1999. Retrieved May 5, 2006, from http://www.asas.org/jas/ symposia/proceedings/0937.pdf.

Baumgard LH, Matitashvili E, Corl BA, Dwyer DA and Bauman DE 2002. Trans-10, cis-12 conjugated linoleic acid decrease lipogenic rates and expression of genes involved in milk lipid synthesis in dairy cows. Journal of Dairy Science 85, 2155-2163.

Beaulieu AD, Drackley JK and Merchen NR 2002. Concentrations of conjugated linoleic acid (cis-9, trans-11-octadecadienoic acid) are increased in tissue lipids of cattle fed a high-concentrate diet supplemented with soybean oil. Journal of Animal Science 80, 847-861.

Belury MA 2002. Dietary conjugated linoleic acid in health: physiological effects and mechanisms of action. Annual Review of Nutrition 22, 505-531.

Duckett SK, Andrae JG and Owens FN 2002. Effect of high-oil corn or added corn oil on ruminal biohydrogenation of fatty acids and conjugated linoleic acid formation in beef steers fed finishing diets. Journal of Animal Science 80, 3353-3360.

Griinari JM, Dwyer DA, McGuire MA, Bauman DE, Palmquist DL and Nurmela KV 1998. Trans-octadecenoic acids and milk fat depression in lactating dairy cows. Journal of Dairy Science 81, 1251-1261.

Harfoot CG and Hazlewood GP 1988. Lipid metabolism in the rumen. In The Rumen Microbial Ecosystem (ed. PN Hobson), pp. 285-322. Elsevier Applied Science Publishers, London, UK.

Ip C, Banni S, Angioni E, Carta G, McGinley J, Thompson HJ, Barbano D and Bauman DE 1999. Conjugated linoleic acid-enriched butter fat alters mammary gland morphogenesis and reduces cancer risk in rats. The Journal of Nutrition 129, 2135-2142.

Kalscheur KF, Teter BB, Piperova LS and Erdman RA 1997. Effect of fat source on duodenal flow of trans-C18:1 fatty acids and milk fat production in dairy cows. Journal of Dairy Science 80, 2115-2126.

Kim YJ, Liu RH, Rychlik JL and Russell JB 2002. The enrichment of a ruminal bacterium (Megasphaera elsdenii YJ-4) that produces the trans-10, cis-12 isomer of conjugated linoleic acid. Journal of the Applied Microbiology 92, 976-982.

Klieve AV, Hennessy D, Quwerkerk D, Forster RJ, Mackie RI and Attwood GT 2003. Establishing populations of Megasphaera elsdenii YE34 and Butyrivibiro fibrisolvens YE 44 in the rumen of cattle fed high grain diets. Journal of the Applied Microbiology 95, 621-630.

Kramer JKG, Fellner V, Dugan MER, Sauer FD, Mosoba MM and Yurawecz MP 1997. Evaluating acid and base catalysts in the methylation of milk and rumen fatty acids with special emphasis on conjugated dienes and total trans fatty acids. Lipids 32, 1219-1228.

Kucuk O, Hess BW and Rule DC 2004. Soybean oil supplementation of a highconcentrate diet does not affect site and extent of organic matter, starch, neutral detergent fiber, or nitrogen digestion, but influences both ruminal metabolism and intestinal flow of fatty acids in limit-fed lambs. Journal Animal Science 82, 2985-2994.

Latham MJ, Storry JE and Sharpe ME 1972. Effects of low-roughage diets on the microflora and lipid metabolism in the rumen. Applied Microbiology 24, 871-877.

Loor JJ, Hoover WH, Miller-Webster TK, Herbein JH and Polan CE 2003. Biohydrogenation of unsaturated fatty acids in continuous culture fermenters during digestion of orchardgrass or red clover with three levels of ground corn supplementation. Journal of Animal Science 81, 1611-1627.
Loor JJ, Ueda K, Ferlay A, Chilliard Y and Doreau M 2004a. Short communication: Diurnal profiles of conjugated linoleic acids and trans fatty acids in ruminal fluid from cows fed a high concentrate diet supplemented with fish oil, linseed oil, or sunflower oil. Journal Dairy Science 87, 2468-2471.

Loor JJ, Ueda K, Ferlay A, Chilliard Y and Doreau M 2004b. Biohydrogenation, duodenal flow, and intestinal digestibility of trans fatty acids and conjugated linoleic acids in response to dietary forage:concentrate ratio and linseed oil in dairy cows. Journal of Dairy Science 87, 2472-2485.

Loor JJ, Ueda K, Ferlay A, Chilliard Y and Doreau M 2005b. Intestinal flow and digestibility of trans fatty acids and conjugated linoleic acids (CLA) in dairy cows fed a high-concentrate diet supplemented with fish oil, linseed oil, or sunflower oil. Animal Feed Science and Technology 119, 203-225.

Martin SA, Fonty G and Michalet-Doreau B 2002. Factors affecting the fibrolytic activity of the digestive microbial ecosystems in ruminants. In Gastrointestinal Microbiology In Animals (ed. SA Martin), pp. 1-17, Research Signpost, Trivandrum, India.

Park Y, Storkson JM, Albright KJ, Liu W and Pariza MW 1999. Evidence that the trans-10, cis-12 isomer of conjugated linoleic acid induces body composition changes in mice. Lipids 34, 235-241.

Peterson DG, Baumgard $\mathrm{H}$ and Bauman DE 2002. Short communication: milk fat response to low doses of trans-10, cis-12 conjugated linoleic acid (CLA). Journal of Dairy Science 85, 1764-1766.

Piperova LS, Sampugna J, Teter BB, Kalscheur KF, Yurawecz MP, Ku Y, Morehouse KM and Erdman RA 2002. Duodenal and milk trans octadecenoic acid and conjugated linoleic acid (CLA) isomers indicate that postabsorptive synthesis is the predominant source of cis-9-containing CLA in lactating dairy cows. Journal of Nutrition 132, 1235-1241.

Roach JAG, Mossoba MM, Yurawecz MP and Kramer JKG 2002. Chromatographic separation and identification of conjugated linoleic acid isomers. Analytical Chemical Acta 465, 207-226.

Robertson JB and Van Soest PJ 1981. The detergent system of analysis and its application to human foods. In The analysis of dietary fiber (ed. WPT James and 0 Theander), pp. 123-129. Marcel Dekker, New York, USA.

Russell JB and Dombrowski DB 1980. Effect of pH on the efficiency of growth by pure cultures of rumen bacteria in continuous culture. Applied and Environmental Microbiology 39, 604-610.

Sackmann JR, Duckett SK, Gillis MH, Realimi CE, Parks AH and Eggelston RB 2003. Effects of forage and sunflower oil levels on ruminal biohydrogenation of fatty acids and conjugated linoleic acid formation in beef steers and finishing diets. Journal of Animal Science 81, 3174-3181.

Shingfield KJ, Reynold CK, Lupoli B, Toivonen V, Yurawecz MP, Delmonte $\mathrm{P}$, Griinari JM, Grandison AS and Beever DE 2005. Effect of forage type and proportion of concentrate in the diet on milk fatty acid composition in cows given sunflower oil and fish oil. Animal Science 80, 225-238.

Stern MD and Hoover WH 1990. The dual flow continuous culture system. In Continuous culture fermenters: frustration or fermentation (ed. MJ Ulyatt, J Lee and D Corson), pp. 17-32. Workshop handbook for NEADSA-ASAS Regional Meeting, Chazy, NY, USA.

Troegeler-Meynadier A, Nicot MC, Bayourthe C, Moncoulon R and Enjalbert $F$ 2003. Effects of pH and concentration of linoleic and linolenic acids on extent and intermediates of ruminal biohydrogenation in vitro. Journal of Dairy Science 8, 4054-4063.

Van Soest PJ, Robertson JB and Lewis BA 1991. Methods for dietary fiber, neutral detergent fiber, and nonstarch polysaccharides in relation to animal nutrition. Journal of Dairy Science 74, 3583-3597.

Wang JH, Song MK, Son YS and Chang MB 2002. Effect of concentrate level on the formation of conjugated linoleic acid and trans-octadecenoic acid by ruminal bacteria when incubated with oilseeds in vitro. Asian-Australian Journal of Animal Science 15, 687-694.

Weller RA and Pilgrim AF 1974. Passage of protozoa and volatile fatty acids from the rumen sheep and from a continuous in vitro fermentation system. The British Journal of Nutrition 32, 341-352.

Whitlock LA, Schingoethe DJ, Hippen AR, Kalscheur KF, Baer RJ, Ramaswamy $\mathrm{N}$ and Kasperson KM 2002. Fish oil and extruded soybeans fed in combination increase conjugated linoleic acids in milk of dairy cows more than when fed separately. Journal of Dairy Science 85, 234-243. 